\title{
Revision of the Monetary Base
}

\author{
ALBERT E. BURGER
}

ATA on the seasonally adjusted monetary base, as computed by this Bank, have been revised to reflect minor changes in the computation of the reserve adjustment magnitude and a change in the method of seasonally adjusting the monetary base. To compute the monetary base, the reserve adjustment magnitude is added to the source base (the uses of which are bank reserves and currency held by the public). The computation of the monetary base is illustrated in Table I.

The main purpose of the reserve adjustment magnitude is to take account of changes in reserve requirement ratios. Total reserves of the banking system are not changed when reserve requirement ratios are changed. However, the amount of deposits that can be supported by a given amount of total reserves is changed. This is taken into account by a change in the reserve adjustment magnitude, and hence the monetary base. For example, when reserve requirement ratios are lowered, the amount of deposits that the amount of total reserves held by the banking sys- tem can support is increased, and hence the reserve adjustment magnitude is increased. The reserve adjustment magnitude is changed by the amount of reserves liberated or absorbed by the change in reserve requirement ratios. This amount is estimated by taking the change in the average reserve requirement ratio and multiplying it by the deposits in the period immediately preceding the reserve requirement change.

The reserve adjustment magnitude also takes account of the effects on required reserves of shifts in the same type of deposits from a bank in one reserve requirement category to a bank in another category. For example, a shift of demand deposits from banks with lower average reserve requirements on demand deposits to banks with higher average reserve requirements on demand deposits will lower the reserve adjustment magnitude. The effects on required reserves of shifts in deposits between demand and time deposits are not included in the reserve adjustment magnitude.

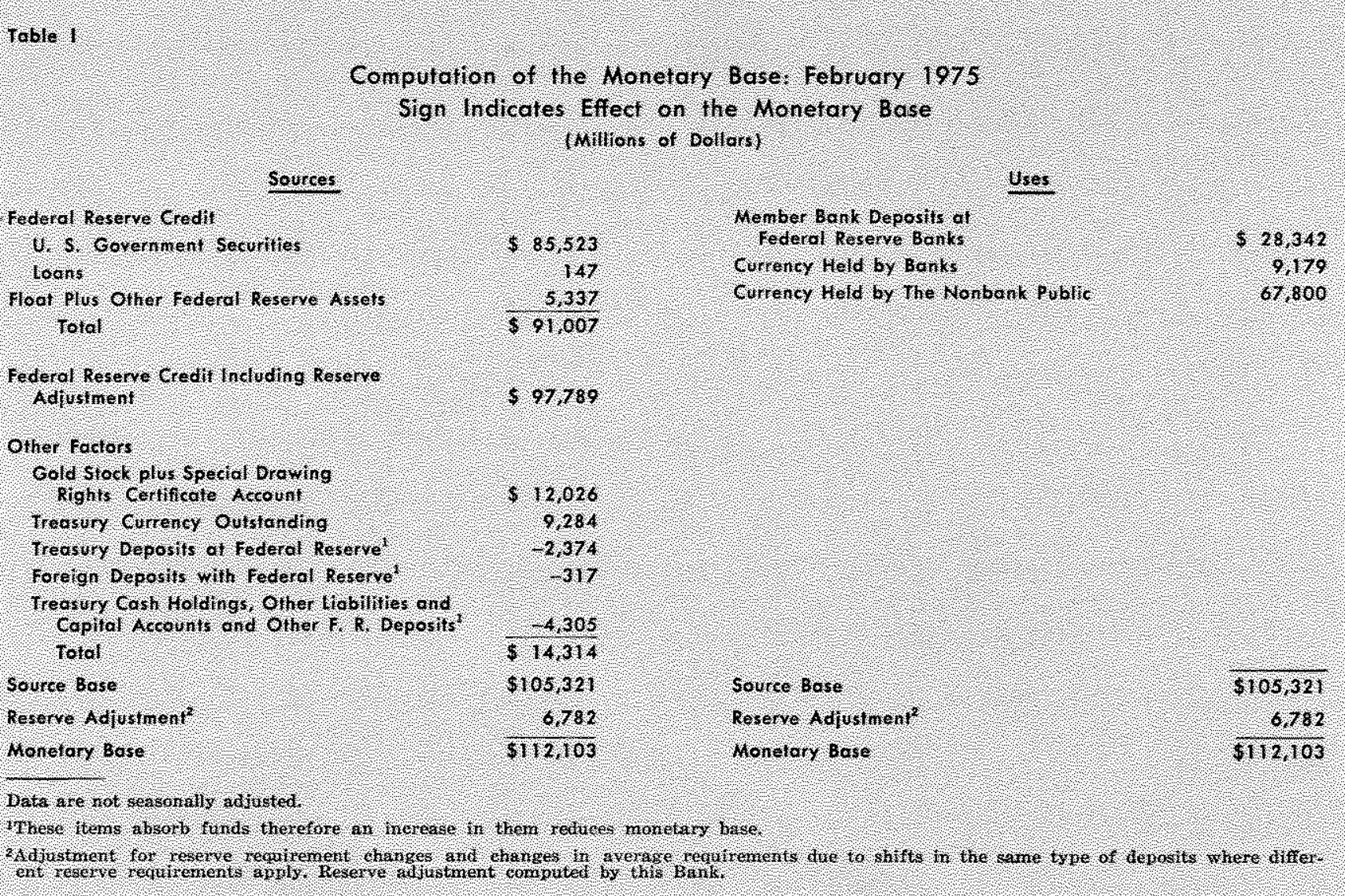




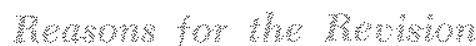

Data for the reserve adjustment magnitude have been revised ( 1 ) to correct a minor computational error in historical data, and (2) to incorporate a new method of seasonally adjusting the monetary base. The effect of the correction of the computational error has been to lower the level of the reserve adjustment magnitude by about $\$ 150$ million over the period from September 1969 to the present.

Prior to this revision, the seasonally adjusted monetary base was computed by first seasonally adjusting the source base (using the Federal Reserve Board version of the $\mathrm{X}-\mathrm{Il}$ variant of the Census Method II seasonal adjustment computer program) and then adding the nonseasonally adjusted reserve adjustment magnitude. Under the new procedure the reserve adjustment magnitude (RAM) is added to the nonseasonally adjusted source base and then the total is seasonally adjusted.

The new seasonal adjustment procedure is appropriate under conditions where open market operations are used to offset the immediate impact of changes in reserve requirement ratios on the banking system. In such cases the source base would change more or less than it would have in the absence of the change in reserve requirements.

For example, in November and December of 1972, the combined effect of the Board of Governors changing Regulations D and J was the release of $\$ 2$ to $\$ 2.5$ billion of reserves to the banking system. The Federal Reserve did not buy Government securities during this period as it had in the same period of previous years. Thus, the source base, which does not include the effects of reserve requirement changes, did not rise as it normally had on a seasonal basis. In each of the eleven years prior to 1972 , nonseasonally adjusted source base rose in the October-December period. From October to December of 1972 the source base decreased by $\$ 583$ million.

Reserve requirements were raised in July 1973 and October 1973. As a consequence, RAM decreased from $\$ 6.950$ billion in June to $\$ 5.127$ billion in October. Over the June-October 1973 period, the nonseasonally adjusted source base rose by about $\$ 4$ billion, compared to an average increase of $\$ 2.1$ billion over the same period in the previous three years and a $\$ 2.2$ billion change in the June-October 1974 period.

If there was only one period where the use of open market operations to offset changes in reserve requirement ratios resulted in movements in the source base that were "unusual" according to previous seasonal behavior, then the seasonal adjustment program, when computing seasonal factors, would treat this "unusual" period as an irregular. Hence, seasonal factors would not be affected significantly. However, if changes in reserve requirements occur repeatedly in the same time periods of successive years, the seasonal factors for the source base would be affected. The change in the seasonal factors for the source base would not reflect a basic change in the seasonal pattern of the source base, but would reflect a seasonal pattern in reserve requirement changes.

From the end of 1966 through February 1975, there have been fifteen changes in reserve requirement ratios on either member bank deposits or other liabilities. Nine changes occurred since late 1972. Reserve requirement changes caused the reserve adjustment magnitude (RAM) to rise from $\$ 3.8$ billion in October 1972 to $\$ 7.1$ billion in December 1972, then fall to $\$ 4.5$ billion by August 1974 and then rise to $\$ 6.8$ billion for February 1975.

Twelve changes in reserve requirement ratios since the end of 1966 have occurred either in the early part or late part of these years. Of these twelve changes, ten changed required reserves by $\$ 400$ million or more. Since late 1972, six of the nine reserve requirement changes have occurred in the period from September through February.

Combining source base and RAM prior to seasonal adjustment offsets part of the apparent bias that has developed in the seasonal factors for the source base due to the recuming changes in reserve requirement ratios. On balance, over the 1969-74 period the seasonal factors for monetary base, seasonally adjusted in this manner, exhibit greater stability than the seasonal factors for the source base.

For the last three years, the effect of changing the method of seasonally adjusting the monetary base has been to leave the changes in levels for the December to April 1972-74 period about the same. The changes in levels from April to October on the new series are, on average, $\$ 454$ million higher. The changes in levels from October-December are, on average, $\$ 475 \mathrm{mil}$ lion lower for the new series.

\section{Bates of rownge}

Tables showing rates of change of the quarterly. average seasonally adjusted monetary base data are presented on page 25. The revision did not significantly affect rates of change over four-quarter or longer periods. For example, from IV/73 to IV/74 


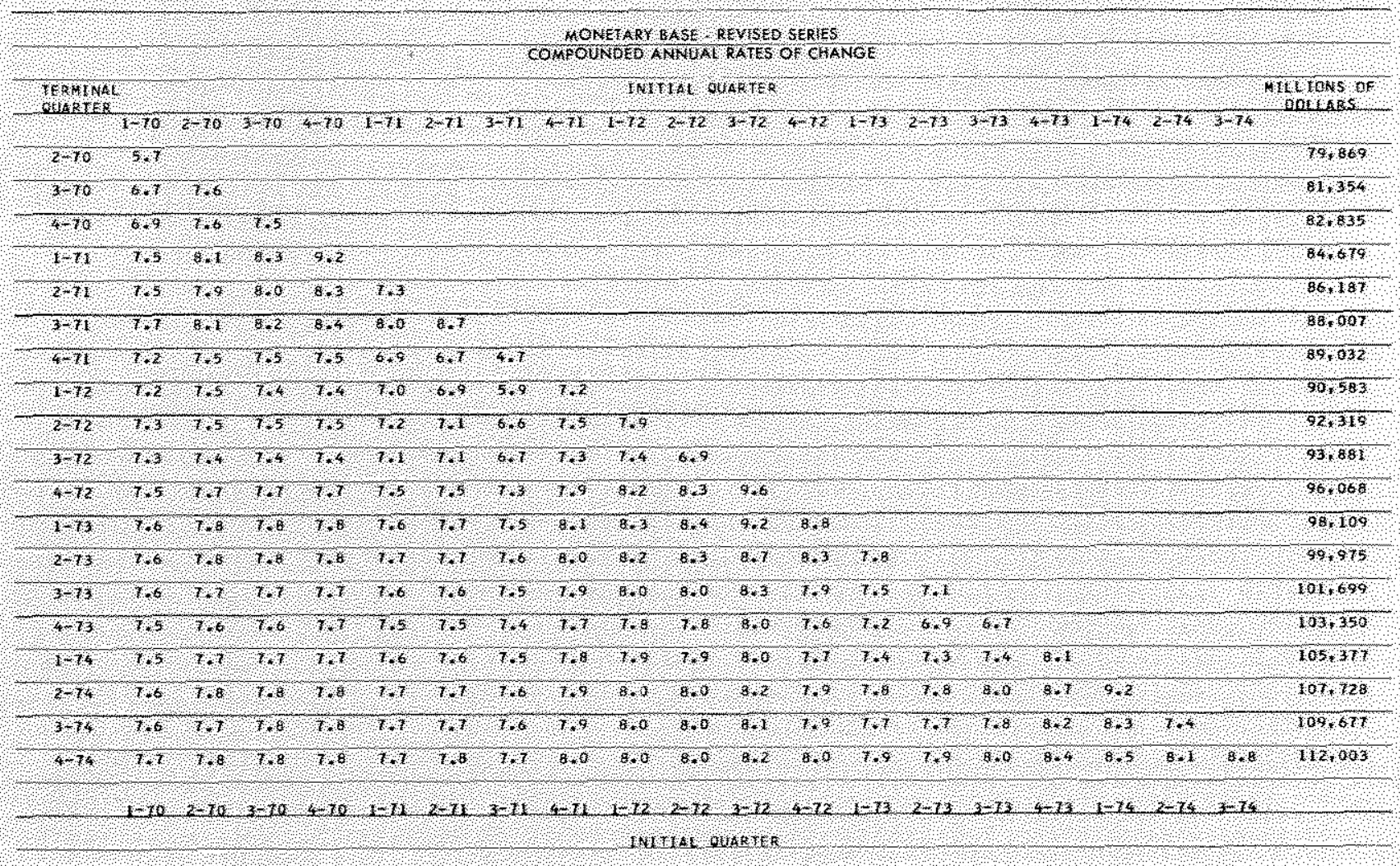

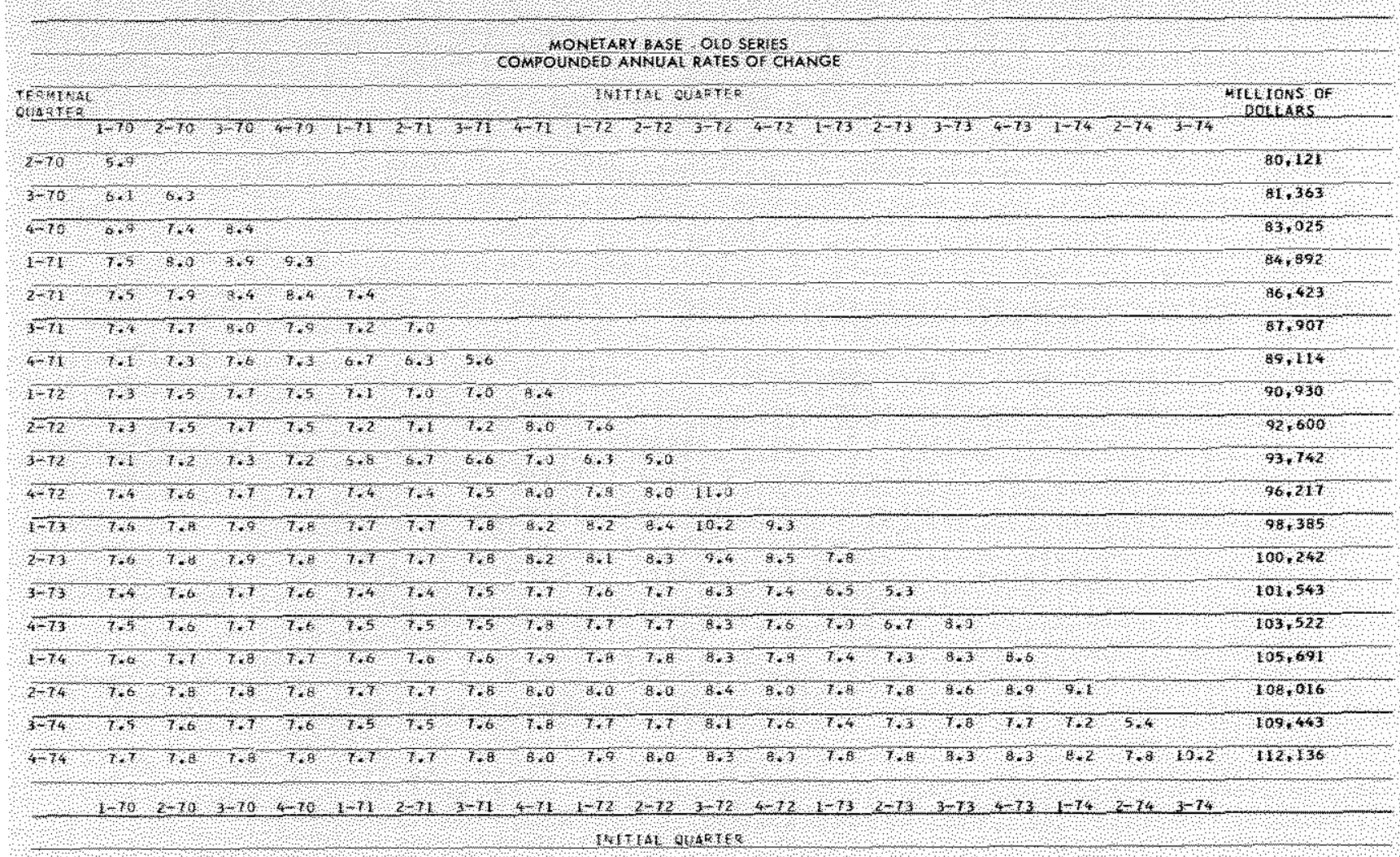




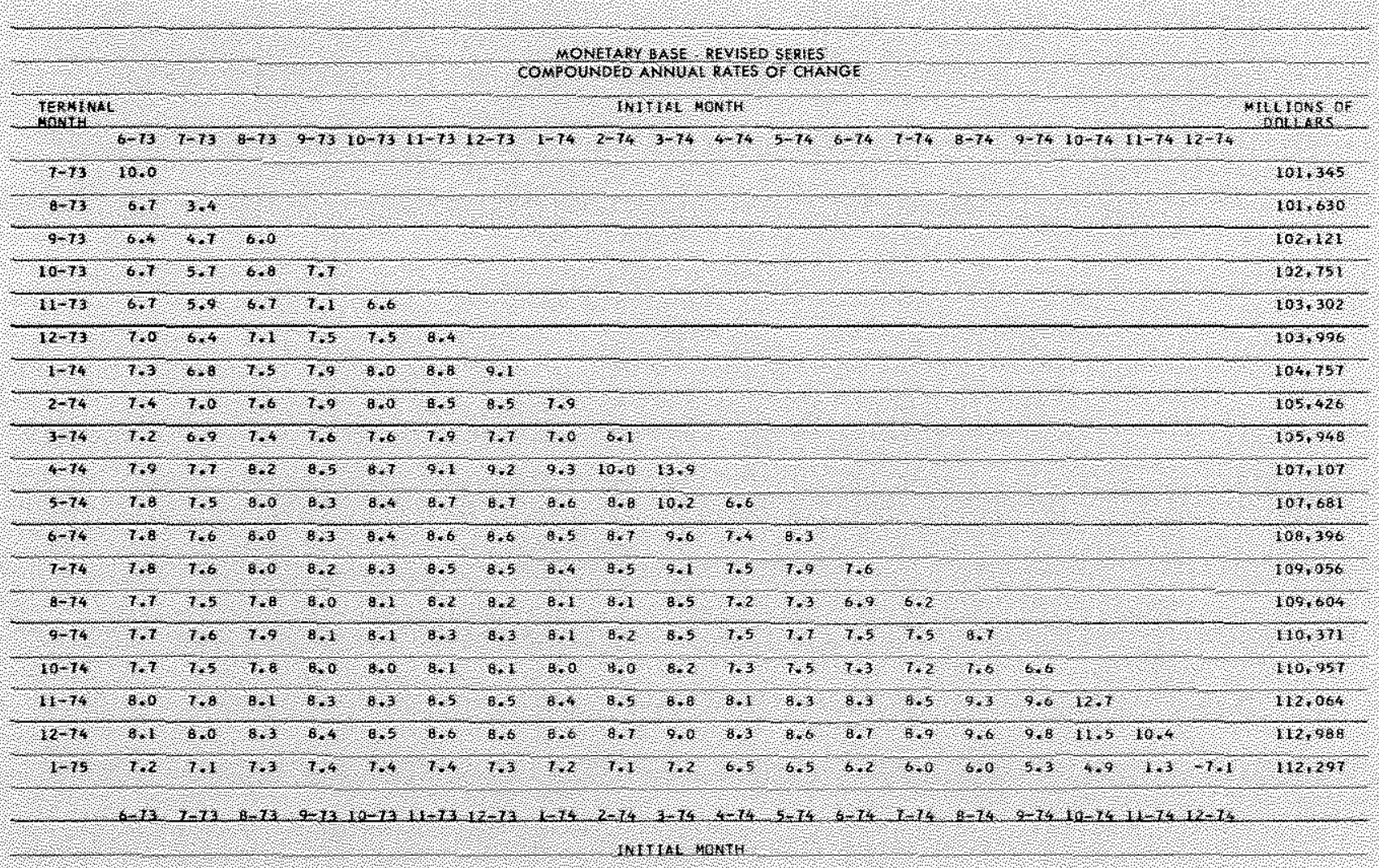

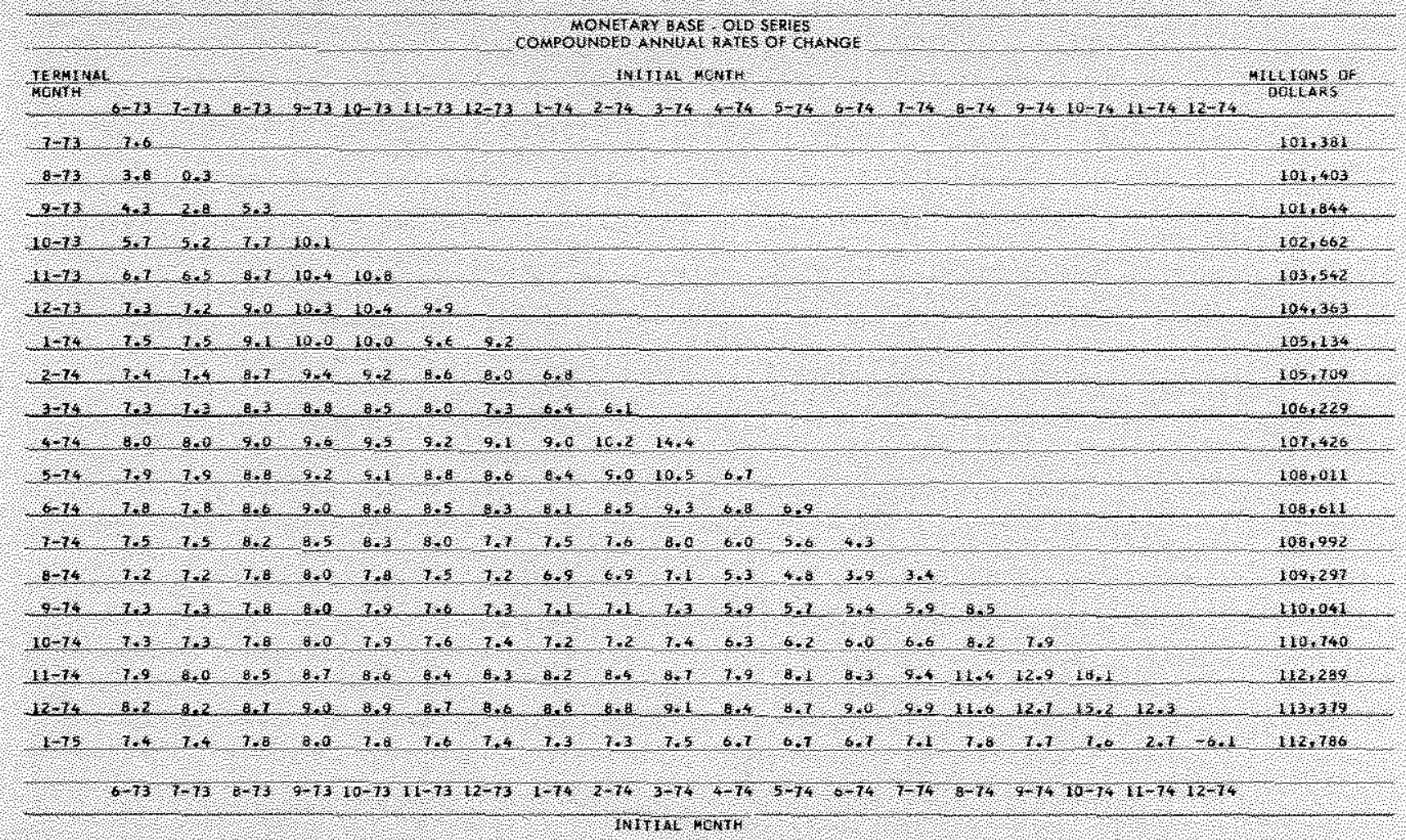




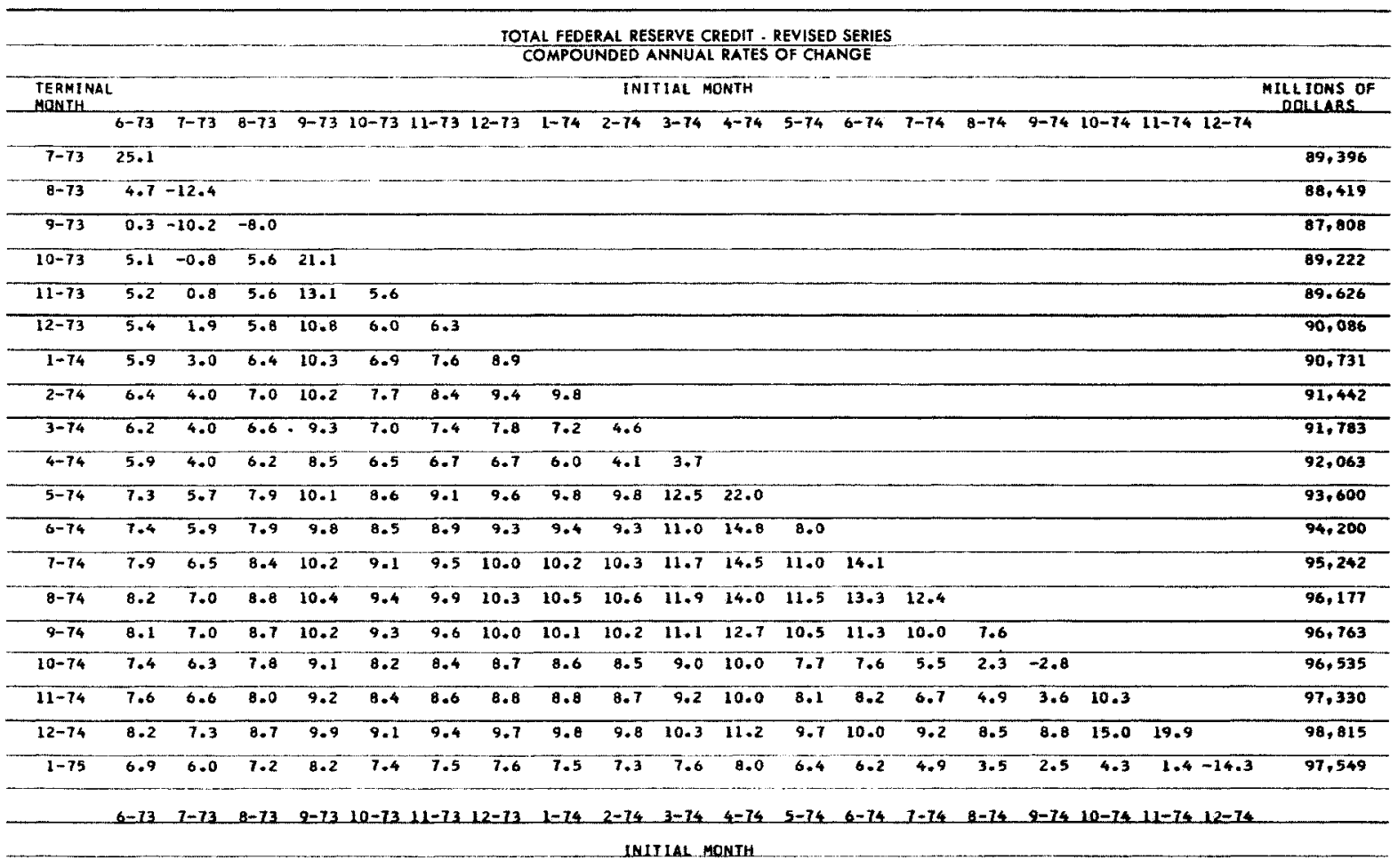

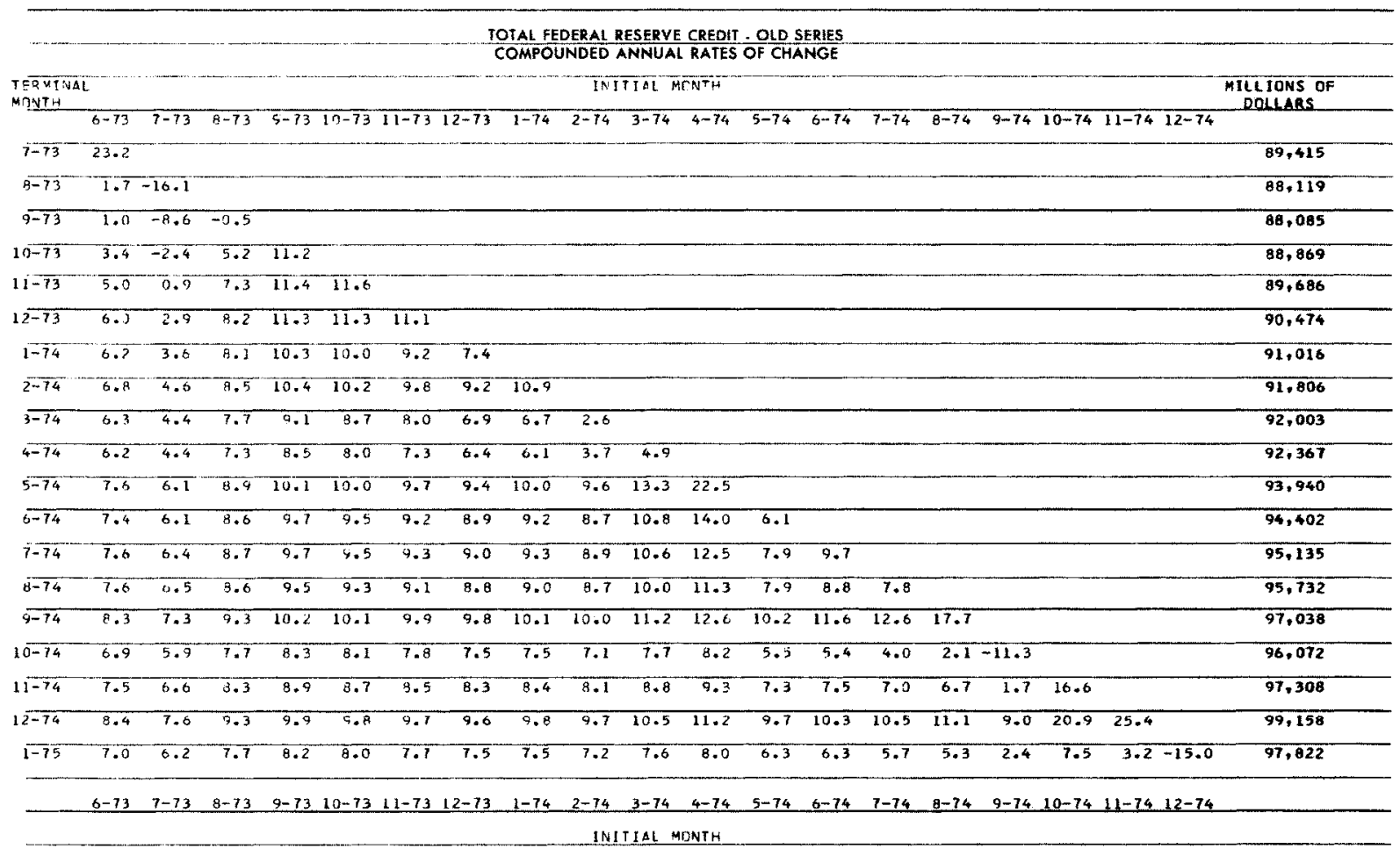


the monetary base grew 8.3 percent on the old basis and 8.4 percent using revised data. The major effect on quarterly growth rates appears in the quarter-toquarter rates of change for the last two quarters in the years $1972-74$.

The revised growth rates for the last quarter of each of these years is lowered from those reported for the old series. For example, the growth rate of monetary base on the old basis in the period III/ $74-I V / 74$ was 10.2 percent, and on the new basis is 8.8 percent. Growth rates of the monetary base from second quarter to third quarter for $1972-74$ were raised. For example, in the period II $/ 74$-III/ $/ 4$ the growth rate of base on the old basis was 5.4 percent, and with the revised data it was 7.4 percent.

Tables showing month-to-month rates of change of the monetary base are shown on page 26 . Using monthly data, the revised monetary base in recent periods shows more of a deceleration in growth than did the previous data. For example, on a revised basis, the monetary base grew at about a 6 percent rate from July 1974 to January 1975 , compared to an 8.4 percent rate over the previous six months. On the old basis, the growth of the base showed very little deceleration over these same periods, from a 7.5 percent rate to about at 7 percent rate in the most recent period.

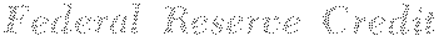

The series on Federal Reserve credit published by this Bank is also adjusted for the effects of changes in reserve requirement ratios and shifts in deposits. Like the source base, the seasonal factors on Federal Reserve credit were influenced by developments such as in November-December 1972. Federal Reserve credit has tended to show a substantial seasonal increase from October to December. The only year in the postwar period that Federal Reserve credit showed a marked decrease from October to December was 1972.

Therefore, the series on Federal Reserve credit has been revised to reflect the minor revisions in computation of RAM and the fact that RAM is now added to Federal Reserve credit and then the total is seasonally adjusted. Tables showing month-to-month rates of change of Federal Reserve credit on the revised and old bases are shown on page 27 . 